\title{
Effect of Dividing the Water Transmission Pipe Line in Modeling Residual Chlorine, Case Study: Isfahan Water Transmission Line
}

\section{Yasaman Frozandeh}

University of Isfahan

Ali Dehnavi ( $\nabla$ a.dehnavi@eng.ui.ac.ir)

University of Isfahan https://orcid.org/0000-0001-5036-8805

Ahmad Shanehsazzadeh

University of Isfahan

\section{Research}

Keywords: drinking water quality, chlorine residual, coefficients of chlorine decay, decay kinetic models, EPANET-MSX

Posted Date: February 22nd, 2021

DOI: https://doi.org/10.21203/rs.3.rs-214682/v1

License: (9) This work is licensed under a Creative Commons Attribution 4.0 International License. Read Full License 

modeling residual chlorine, case study: Isfahan water

a.dehnavi@eng.ui.ac.ir a.shanehsazzadeh@eng.ui.ac.ir

$11 *$ Correspondence: a.dehnavi@eng.ui.ac.ir 


\section{Abstract}

14 In assessing the quality of drinking water in transmission and distribution lines, the

15 study on chlorine reactions is of particular importance. Chlorine decay happens in bulk

16 and wall and it is mainly affected by the water age which depends on the transmission

17 line length. Residual chlorine concentration in Isfahan water transmission line (IWTL)

18 is simulated through three decay models, namely the first order, parallel first order and

19 second order single reactant (SR model) which incorporated in EPANET and EPANET

20 MSX, respectively. The results of the models are compared through two approaches,

21 one is the one-part approach (OPA) whereby chlorine decay simulation is performed

22 taking into account the whole line as one section and the second is multi-part approach

23 (MPA) whereby the line is divided into two sections and decay coefficients of chlorine

24 for each section are separately determined. Results show that in the OPA, the SR model in summer and the parallel model in winter are the best kinetic models. While in the MPA, the results of first order model has the same order of accuracy as the more complex models of parallel and SR models.

29 provides acceptable level of accuracy in compare to the complex models applied in 
EPANET MSX s/w. The average RMSE volumes are reduced from 0.078 in OPA to 0.029 in MPA in summer and from 0.059 to 0.015 in winter, indicating that the dividing the line in simulation procedure and considering the individual decay coefficient for each part, considerably improves the results, more effectively than the application of

34 advanced decay models.

35 Keywords: drinking water quality, chlorine residual, coefficients of chlorine decay,

36 decay kinetic models, EPANET-MSX.

\section{Introduction}

In the design and operation of drinking water distribution systems, the quality of the water is one of the most important concern. Different methods of disinfection is applied to preserve water quality [1-3]. The main reasons to disinfect the drinking water

41 is due to pathogenic microorganisms entering through the drinking water distribution system [4,5]. The residual amount of the disinfectant during storage and distribution of drinking water is the most important factor to select the kind of disinfectant. Chlorine

44 is the most common disinfectant in water supply systems due to its residual preservation,

45 effective performance and economical aspect [4,6]. Chlorine decays along pipes and in

46 storage reservoirs in water content and pipe walls. The reactions of chlorine with 
organic and inorganic substances in the volume of water is called bulk decay, while the reactions with biofilms and materials on the wall of the pipes and reservoirs is called wall decay $[1,2,7]$. The bulk decay reactions depend on chemicals and microbiological

50 quality and water age. The water age is the time which takes for a parcel of water to

51 travel from water treatment plant to a node in a the line or in the network [8]. The wall

52 decay reactions are affected by characteristics of the pipes and reservoirs[7,9-11].

53 These reactions reduce concentration of chlorine. Thus, the risk of microbial

54 contamination increases and more chlorine should be injected to maintain the minimum

55 chlorine content. Increasing chlorine concentration in the water supply accelerates pipe

56 corrosion, changes the water taste and odor and increases disinfection by-products

57 (DBPs) [11,12]. To find optimal conditions for chlorine injection in drinking water

58 distribution systems or transmission lines, the study on the bulk and wall chlorine decay reactions is essential. The decay of chlorine involves complex reactions that is conventionally simplified to first order kinetic in water quality modeling. To improve this traditional model, different advanced decay kinetic expressions, i.e. $\mathrm{n}^{\text {th }}$ order, parallel first order, limited

63 first order, single-reactant second order (SR) and two-reactant second order (2R) model 
64 are developed $[3,13,14]$. Eqs. (1) to (7) list the differential expressions of kinetic models

$65\left(\mathrm{dc}_{\mathrm{cl}} / \mathrm{dt}\right)$ proposed for chlorine bulk decay.



66 where $c_{c l}$ is the concentrations of chlorine $\left(\mathrm{mg} \mathrm{L}^{-1}\right), \mathrm{k}_{\mathrm{b}}$ is bulk decay coefficient

$67\left(\right.$ time $\left.^{-1}\right), \mathrm{n}$ is order of reaction, $\mathrm{c}_{\mathrm{cl}}{ }^{*}$ is the limited concentration of chlorine $\left(\mathrm{mg} \mathrm{L}^{-1}\right), \mathrm{k}_{\mathrm{b} 1}$

68 and $\mathrm{k}_{\mathrm{b} 2}$ are bulk decay rate coefficients for fast and slow reactions, respectively (time ${ }^{-}$

$69^{1}$ ), $\mathrm{x}$ is a fraction of the initial concentration, [React] is the concentration of the species

70 that react with chlorine, $\mathrm{c}_{\mathrm{f}}$ and $\mathrm{c}_{\mathrm{s}}$ are the concentrations of fast and slow reducing agents

71 respectively, and $\mathrm{k}_{\mathrm{bf}}$ and $\mathrm{k}_{\mathrm{bs}}$ are bulk decay rate coefficients for fast and slow reactions

72 respectively $\left(\mathrm{L} \mathrm{mg}^{-1}\right.$ time $\left.^{-1}\right) \cdot \mathrm{x}_{\mathrm{i}, \mathrm{t}}$ is the concentration of the $\mathrm{i}^{\text {th }}$ aqueous species at time $\mathrm{t}$

73 that reacts with chlorine with rate constant $\mathrm{k}_{\mathrm{i}}$ [15]. Parallel and second-order $2 \mathrm{R}$ models 
74 are developed, because some compounds in drinking water e.g. iron are fast reactive,

75 whereas some e.g. manganese are slow reactive $[3,10,13]$. The required time for fast

76 reactions is about 3 to $4 \mathrm{~h}$ [7]. Several studies are performed to investigate on the most

77 suitable bulk decay coefficients $[3-5,10,16]$. The SR model is simulated by combined

78 concentration of chlorine and other substances in the kinetic equations of decay. Eqs.

79 (8) to (10) formulated by Boccelli et al to simulate SR model [1].

$$
\begin{aligned}
& a A+b B \rightarrow \rho P \\
& \frac{d C_{A}}{d t}=-k_{A} C_{A} C_{B} \cdot \frac{d C_{B}}{d t}=-k_{B} C_{A} C_{B} \\
& \frac{k_{A}}{a}=\frac{k_{B}}{b}
\end{aligned}
$$
where $C_{A}$ is the concentration of chlorine, $C_{B}$ is the concentration of reactive

81 component, $\mathrm{k}_{\mathrm{A}}$ is decay rate coefficient for the chlorine, $\mathrm{k}_{\mathrm{B}}$ is decay rate coefficient for the reactive component, and a and $\mathrm{b}$ are stoichiometry coefficients $[1,17]$.

$$
\frac{d C}{d t}=\frac{4 k_{w} k_{f}}{D\left(k_{w}+k_{f}\right)} C
$$

85 where $\mathrm{k}_{\mathrm{f}}$ is the mass transfer coefficient (length divided by time), $\mathrm{k}_{\mathrm{w}}$ is the wall

86 reaction rate coefficient (length divided by time) and $\mathrm{D}$ is the pipe's diameter 
$87[5,16,18,19]$. The wall decay coefficient depends on characteristics of the distribution

88 pipes such as diameter, age, roughness, pipe material and the volume of biofilm formed

89 on the pipe surfaces $[7,9,11]$.

90 In order to simulate chlorine decay reactions, the bulk decay coefficient $\left(\mathrm{k}_{\mathrm{b}}\right)$ and the

91 wall decay coefficient $\left(\mathrm{k}_{\mathrm{w}}\right)$ need to be specified. The $\mathrm{k}_{\mathrm{b}}$ is determined by bottle tests

92 and $\mathrm{k}_{\mathrm{w}}$ is determined by calibration of distribution systems or transmission lines

93 through the simulation [2].

94 EPANET is a series of modeling software package developed by the United States

95 Environmental Protection Agency's (EPA) for the hydraulic and quality simulation of

96 water distribution systems [2,3,5]. The water quality simulation in the EPANET2.0 is

97 limited to only a single chemical species. The Multi-Species extension, EAPANET

98 MSX, which was developed in 2008, provides qualitative simulation with a multi-

99 species approach [14,18-20]. This new extension has brought enhanced capabilities for

100 the simulation of chlorine residuals in water supply systems that allows the modeling

101 of chemical reactions of any level of complexity. In this extension, kinetics of chemical

102 reactions are introduced to the model through a set of Ordinary Differential Equations

103 (ODEs) [21]. 
104 Fisher et al. [3] compared three bulk decay models (SR, 2R and VRC model) in the

105 EPANET MSX. According to their results, 2R and VRC models were more accurate

106 [3]. Monteiro et al. [18] evaluated the performance of the 2R model, first and nth order

107 decay kinetics in a transmission line by using EPANET MSX. Their simulation results

108 show that these models described the bulk decay reactions of chlorine consumption

109 with a same accuracy [18]. The chlorine decay was simulated using a second-order

110 model in the EPANET MSX by Ohar et al. [17]. They proposed a new method for

111 designing, installing and disinfection operation in water distribution systems by

112 optimizing the amount of injected chlorine [17]. Tiruneh et al. [5] found that second

113 order kinetics for bulk decay calibration was more accurate than first order model in

114 simulation of the Matsapha town water network. Applying first order model for

115 simulating chlorine wall decay in EPANET s/w, the value of the wall coefficient by

116 trial and error procedure was obtained $0.05 \mathrm{~m} \mathrm{~d}^{-1}[5]$.

117 Carmen et al. [22] applied EPANET2.0 software to model the residual chlorine in

118 an urban distribution network with a population of 50,000. The bulk decay coefficient

119 was determined $0.85 \mathrm{~d}^{-1}$ and the wall reaction coefficients were assigned from 0.013 to

$120 \quad 0.057 \mathrm{~m} \mathrm{~d}^{-1}[22]$. 
121 Pedro Castro et al. [23] emphasized on the importance of chlorine wall decay in

122 relation to bulk decay reactions in water distribution network in Luzada, Portugal. The

123 bulk decay coefficient by bottle tests and the wall decay coefficient in the first order

124 reaction were determined as $0.343 \mathrm{~d}^{-1}$ and $0.0021 \mathrm{~m} \mathrm{~second}^{-1}$ respectively [23].

125 Mostafa et al. [4] investigated the effect of water-age as a measuring and controlling

126 tool to estimate chlorine concentration at different water network points. They found

127 that EPANET model is accurate in predicting chlorine concentration at low water age

128 nodes [4].

129 In this study, the effect of dividing the water transmission pipe line in modeling

130 procedure, on improving residual chlorine prediction is of concern. For this purpose,

131 the chlorine concentration of great Isfahan Water Transmission Line (IWTL) is

132 simulated. The IWTL is the longest and most important water transmission route in the

133 central Iran. First order decay model, parallel first and second order single reactant (SR)

134 models are applied and the results are compared. The EPANET and EPANET MSX

$135 \mathrm{~s} / \mathrm{w}$ are applied for simulation. Bottle tests are carried out to assess chlorine

136 consumption kinetics and estimate bulk decay rate coefficients. The simulations are

137 applied through one-part approach (OPA) and multiple-part approach (MPA). The OPA 
applies single decay coefficient for whole the line. In the MPA, the transmission line is

139 separated into smaller sections (in this study: two sections) to apply several coefficients

140 The article is outlined as follow: the case study is introduced in Sec. 2, methodology

141 and experimental work is described in Sec. 3, the results of the Bottle tests for assessing

142 chlorine consumption kinetics are presented in Sec. 3. Simulation procedure in

143 EPANET and EPANET- MSX is described in Sec. 4, followed by the results and

144 discussion in Sec. 5. The conclusion remarks are presented in Sec. 6

\section{2. Case study}

146 Baba-Sheikhali water treatment plant located at the Southwest of Isfahan province,

147 Iran, supplies the drinking water for more than 4 million consumers from Zayandehrod

148 river. Outflow rate of the water treatment plant in summer and winter are about 11.2

149 and $8.5 \mathrm{~m}^{3}$ secund $^{-1}$, respectively. The study is performed on the IWTL. The total length

150 of IWTL is $258 \mathrm{~km}$ starting from Baba-Sheikhali water treatment plant, ending at Naein

151 city in northeast of Isfahan province (Figure 1). The IWTL with 38 nodes, three

152 pumping stations and two reservoirs is one of the important and strategic water lines in

153 the central Iran. Physical characteristics of some important nodes of the IWTL are

154 tabulated in Table 1. 
Table 1: Physical characterizes of important nodes in IWTL

\begin{tabular}{|c|c|c|c|c|}
\hline $\begin{array}{c}\text { Node } \\
\text { number }\end{array}$ & Node name & $\begin{array}{c}\text { Distance from } \\
\text { treatment } \\
\text { plant site }(\mathrm{km})\end{array}$ & $\begin{array}{c}\text { pipe material between } \\
\text { two nodes }\end{array}$ & $\begin{array}{c}\text { pipe age } \\
\text { (year) }\end{array}$ \\
\hline 2 & Oshtorjan & 17.7 & concrete & 30 \\
\hline 3 & Falavarjan & 28.7 & Prestressed-concrete & 30 \\
\hline 4 & Felman & 39.7 & Prestressed-concrete, steel & 30 \\
\hline 5 & Hezarjerib (reservoir) & 52.7 & Prestressed - concrete & $\begin{array}{c}22-39 \\
\text { var. }\end{array}$ \\
\hline 6 & Abshar & 56.7 & Prestressed - concrete & 33 \\
\hline 7 & Gavart (reservoir) & 66.7 & Prestressed-concrete, steel & 14 \\
\hline 8 & Timyart & 101.7 & Steel & 28 \\
\hline 11 & Naein (reservoir) & 258 & GRP-Steel-ductile iron & $7-28$ \\
\hline
\end{tabular}

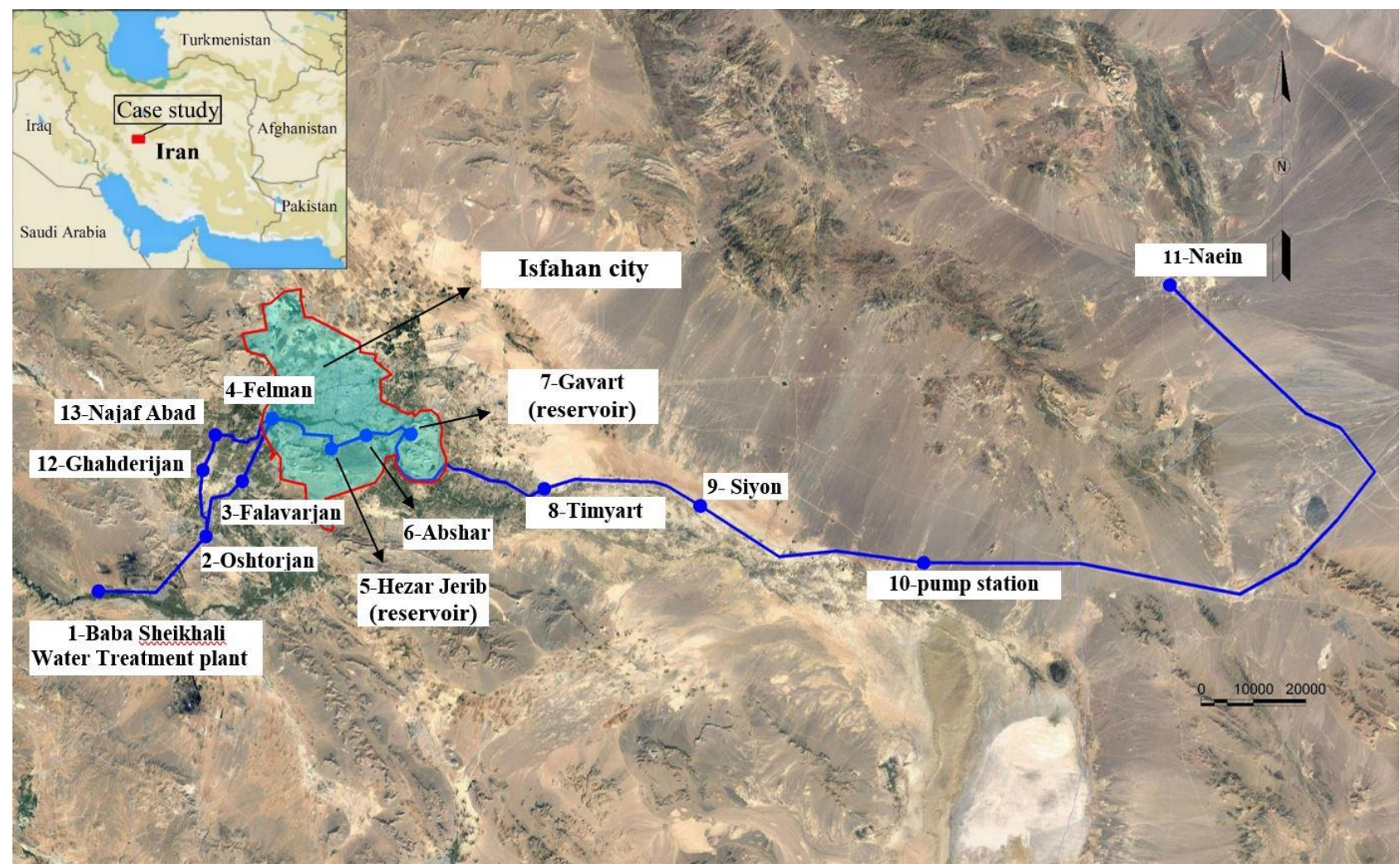




\section{Experimental procedure, bulk decay coefficient derivation}

160 Bulk decay coefficient, $\mathrm{k}_{\mathrm{b}}$, is the key parameter in the decay kinetics expressions.

161 Bulk decay coefficients are commonly derived through the bottle tests $[9,24]$. The

162 results are case specific depending on various parameters [4,10,16]. Jaichan et al. [2]

163 performed thirteen bulk tests at the different water temperatures over a period of $50 \mathrm{~h}$.

164 The Bulk decay coefficient, $\mathrm{k}_{\mathrm{b}}$, ranged from 0.18 to $0.41 \mathrm{~d}^{-1}$ [2]. Jico et al. [25]

165 determined the residual chlorine concentration by bottle tests in spring and autumn

166 (water temperature $15^{\circ} \mathrm{C}$ ), summer (water temperature $25^{\circ} \mathrm{C}$ ) and winter (temperature

$167 \quad 6^{\circ} \mathrm{C}$ ) as $0.38,0.4$ and $0.3 \mathrm{~d}^{-1}$ respectively [25].

168 In this study, the experimental design consists of collecting a set of samples from

169 the effluent Baba-Sheikhali water treatment plant prior to enter the water transmission

170 line. A Hach pocket colorimeter model 5870012 with Diethyl-P-phenylene Diamine

171 (DPD) as an indicator was applied to measure free residual chlorine concentration of

172 the samples. Tests were performed from the water age 0 to $82 \mathrm{~h}$ in summer and 0 to 92

$173 \mathrm{~h}$ in winter temperatures. The first sample was measured in place just after it was taken

$174\left(\mathrm{at}_{0}\right)$ in place. The other bottles were put in incubator and were set at temperatures $6^{\circ} \mathrm{C}$

175 and $18^{\circ} \mathrm{C}$ as an average water temperature in winter and summer, respectively. 
176 Determination of bulk decay coefficients based on water age were derived for OPA and

177 MPA at $6^{\circ} \mathrm{C}$ and $18^{\circ} \mathrm{C}$, where the water age in the OPA is $0-82 \mathrm{~h}$, while in the MPA it

178 is $0-18 \mathrm{~h}$ in the first part and $18-82 \mathrm{~h}$ in the second part at $\mathrm{T}=18^{\circ} \mathrm{C}$.

179 The result of the measurement of chlorine concentration at $18^{\circ} \mathrm{C}$ is shown in Figure

1802 , where the continuous line is fitted to the whole data in the range $0-82 \mathrm{~h}$. Accordingly,

181 the bulk decay coefficient, $\mathrm{k}_{\mathrm{b}}$ is equal to $0.286 \mathrm{~d}^{-1}$. According to the Figure $2, \mathrm{k}_{\mathrm{b}}$ in the

182 first part with water age in range $0-18 \mathrm{~h}$ is equal to $0.583 \mathrm{~d}^{-1}$ (dotted line) and in the

183 second part where the water age is in range $18-82 \mathrm{~h}$ is equal to $0.216 \mathrm{~d}^{-1}$ (dashed line).

184

185

186

187

188

189

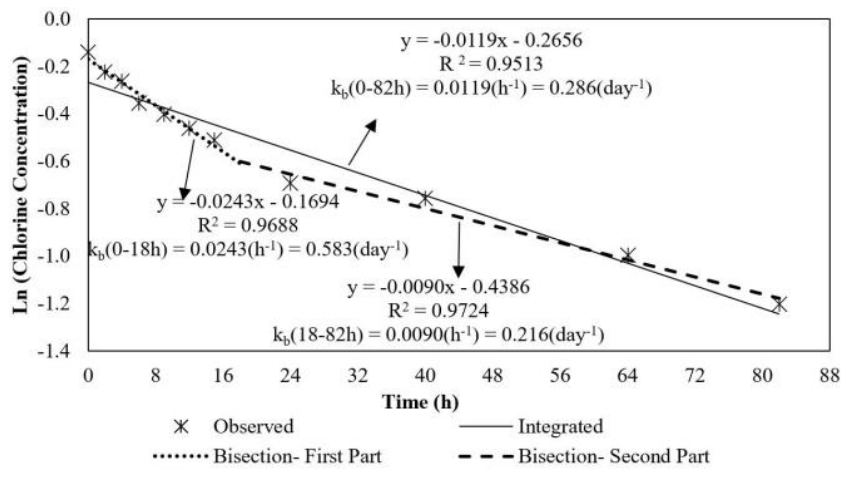

Figure 2: Bulk decay coefficient at $18^{\circ} \mathrm{C}$ with OPA and MPA using the bottle test

The estimation of $k_{b 1}$ (the coefficient of fast reaction) and $k_{b 2}$ (the coefficient of slow reaction) is necessary to apply the parallel first order model. Therefore, the $\mathrm{k}_{\mathrm{b}}$ coefficients for kinetic models at $18^{\circ}$ and $6^{\circ}$ are calculated as shown in Figure 2. The results are summarized in Table 2. 


\begin{tabular}{|c|c|c|c|c|c|c|c|c|c|c|}
\hline \multirow{3}{*}{$\begin{array}{c}\mathrm{T} \\
\left({ }^{\circ} \mathrm{C}\right)\end{array}$} & \multirow{3}{*}{ Approach } & \multirow{3}{*}{ Parts } & \multirow{2}{*}{\multicolumn{2}{|c|}{$\begin{array}{l}\text { First Order } \\
\qquad\left(\mathrm{d}^{-1}\right)\end{array}$}} & \multirow{2}{*}{\multicolumn{2}{|c|}{$\begin{array}{l}\text { Second Order } \\
\left(\text { L.mg }^{-1} \cdot \mathrm{d}^{-1}\right)\end{array}$}} & \multicolumn{4}{|c|}{ Parallel $\left(\mathrm{d}^{-1}\right)$} \\
\hline & & & & & & & \multicolumn{2}{|c|}{ Fast } & \multicolumn{2}{|c|}{ Slow } \\
\hline & & & $\mathrm{k}_{\mathrm{b}}$ & $\mathrm{R}^{2}$ & $\mathrm{k}_{\mathrm{b}}$ & $\mathrm{R}^{2}$ & $\mathrm{k}_{\mathrm{b}}$ & $\mathrm{R}^{2}$ & $\mathrm{k}_{\mathrm{b}}$ & $\mathrm{R}^{2}$ \\
\hline \multirow{3}{*}{18} & OPA & All (0-82h) & 0.286 & 0.95 & 0.590 & 0.98 & 0.828 & 0.98 & 0.286 & 0.95 \\
\hline & \multirow{2}{*}{ MPA } & First $(0-18 \mathrm{~h})$ & 0.583 & 0.97 & 0.821 & 0.98 & 0.828 & 0.98 & 0.583 & 0.97 \\
\hline & & Second (18-82h) & 0.216 & 0.97 & 0.557 & 0.95 & - & - & 0.216 & 0.97 \\
\hline \multirow{3}{*}{6} & OPA & All (0-92h) & 0.103 & 0.92 & 0.144 & 0.95 & 0.401 & 1 & 0.103 & 0.92 \\
\hline & \multirow{2}{*}{ MPA } & First $(0-22 h)$ & 0.204 & 0.95 & 0.264 & 0.96 & 0.401 & 1 & 0.204 & 0.95 \\
\hline & & Second (22-92h) & 0.062 & 0.99 & 0.098 & 1 & - & - & 0.062 & 1 \\
\hline
\end{tabular}

191 The results of the bottle tests show that $\mathrm{k}_{\mathrm{b}}$ in the first and second order reactions is

192 significantly different between the first and second parts of the line Table 2 . In addition,

193 they are significantly different from its value for the entire line, which is applied in

194 OPA. Because the chlorination is carried out once in IWTL (in Baba-Sheikhali

195 treatment plant), the concentration of chlorine in the first part is much higher than the

196 concentration in the second part.

197 The derived coefficients are applied in simulation of bulk decay (Eqs. $(1,4,5))$. In

198 the parallel model, Eq. (4), $\mathrm{k}_{\mathrm{b} 1}$ is obtained from the first $4 \mathrm{~h}$ of reaction and the $\mathrm{k}_{\mathrm{b} 2}$ from

199 the beginning of chlorination up to the end node. In IWTL, in summer at the Falavarjan

200 (node 3 in Figure 1) and in winter at Oshtorjan (node 2 in the Figure 1) water age 
reaches 3 to $4 \mathrm{~h}$. Thus, these two nodes are respectively considered as the end of fast

chlorine reactions in summer and winter.

\section{Simulation procedure in EPANET.}

IWTL is simulated in EPANET s/w in hydraulic and quality manners. EPANET

205 s/w performs extended period simulation of hydraulic and water quality behaviour. The

206 Hazen-Williams head loss formula is applied in simulation. The water quality model in

207 EPANET s/w applies nth order kinetics to model reactions in the bulk flow and applies

208 zero or first order kinetics to model reactions at the pipe wall [8]. Chlorine residual

209 concentration is then assessed in the line or network by inputting wall and bulk decay

210 coefficients.

$211 \quad$ 4.1. Hydraulic simulation

212 Applying field pressure data at different nodes, the hydraulic model of the line is

213 calibrated and verified. The comparison between the results of the model and

214 measurements for the selected nodes are summarized in Table 3. The root mean square

215 error (RMSE) of the simulation is 4.09 meters in summer and 4.24 meters in winter.

216 The correlation coefficients $\left(\mathrm{R}^{2}\right)$ between the results of the model and measurement are

2170.958 and 0.978 for summer and winter, respectively, indicating that the hydraulic 
218 simulation is in acceptable level of accuracy.

219 The schematics of transmission line and the hydraulic simulation results for summer

220 flow condition is shown in Figure 3. The node colors in Figure 3 represent the water

221 age and the numbers adjacent to the lines show the maximum flow rate ( $\mathrm{L} \mathrm{sec}^{-1}$.). Water

222 age is important in this analysis because when it is increased, the residual concentration

223 of disinfectant decreases and microorganisms' growth increases [2].

224 Table 3: Results of simulation and measured pressure in some nodes of IWTL in summer

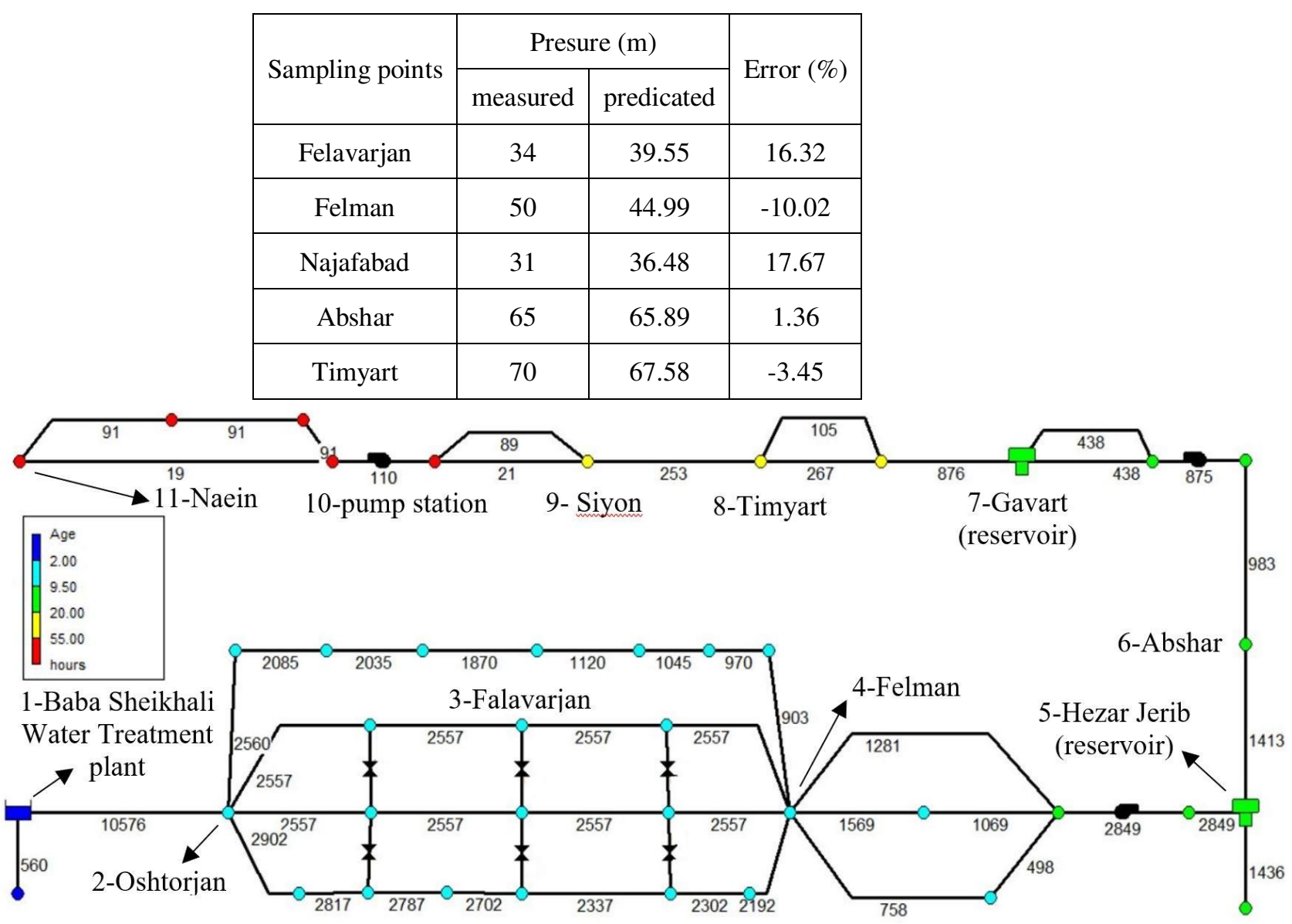

Figure 3: Schematic diagram of IWTL and simulation results in summer 
Applying the first model in EPANET $2.0 \mathrm{~s} / \mathrm{w}$ and second order SR model and parallel first order model in EPANET-MSX s/w, the residual chlorine concentration in

230 IWTL is simulated. Since the IWTL is too long, the water residence time in the pipes

231 is lengthy too. This will decline the validity of applying a single decay coefficient for

232 the whole line. Therefore, the IWTL is simulated in two approaches included OPA and

233 MPA. In the OPA, only one bulk decay coefficient and one wall decay coefficient are

234 applied for all pipes in the line. This is a usual method to simulate residual chlorine

235 concentration in transmission lines and water distribution networks [2,4]. In MPA, as a

236 new approach, different bulk and wall decay coefficients are considered. In this study,

237 IWTL line is divided to two parts and therefore, two bulk and wall decay coefficients

238 are considered for simulation.

The Gavart reservoir (node 7 in Figure 3) is selected as the separator in MPA for

240 two reasons. First the Gavart reservoir is the last node in the Isfahan city along the

241 IWTL, the second is the number of the available field data to calculate RMSE. Thus, in

242 the MPA, the IWTL from the Baba-Sheikhali treatment plant to Gavart reservoir and

243 from the Gavart reservoir to Naein are considered as the first and second part, 
244 respectively. The average water age in the first and second sections is about 18 and 82

$245 \mathrm{~h}$ in summer and 22 and $92 \mathrm{~h}$ in winter, respectively.

246 Applying the first order, parallel, and second order SR models, chlorine bulk decay

247 of IWTL is simulated. The first order model Eq. (1) is simulated in EPANET2.0 s/w.

248 The EPANE MSX is applied for simulation of the parallel Eq. (4) and second order SR

249 models Eq. (5).

250 Wall decay coefficient is estimated by first model kinetic Eq. (11) and the trial and

251 error in the EPANET2.0 s/w to achieve the minimum difference between simulated and

252 measured chlorine concentrations at the study nodes. Field chlorine concentration

253 measured in selected nodes of IWTL by Isfahan Water and Wastewater Organization.

254 Note that in the OPA, the model is calibrated with a single wall coefficient and in

255 the MPA, two wall coefficients are considered. The best wall coefficient is chosen based

256 on the least RMSE [5,26].

257 The procedure of hydraulics and chlorine residual concentration for OPA and MPA

258 in EPANET is summarized in Figure 4. 

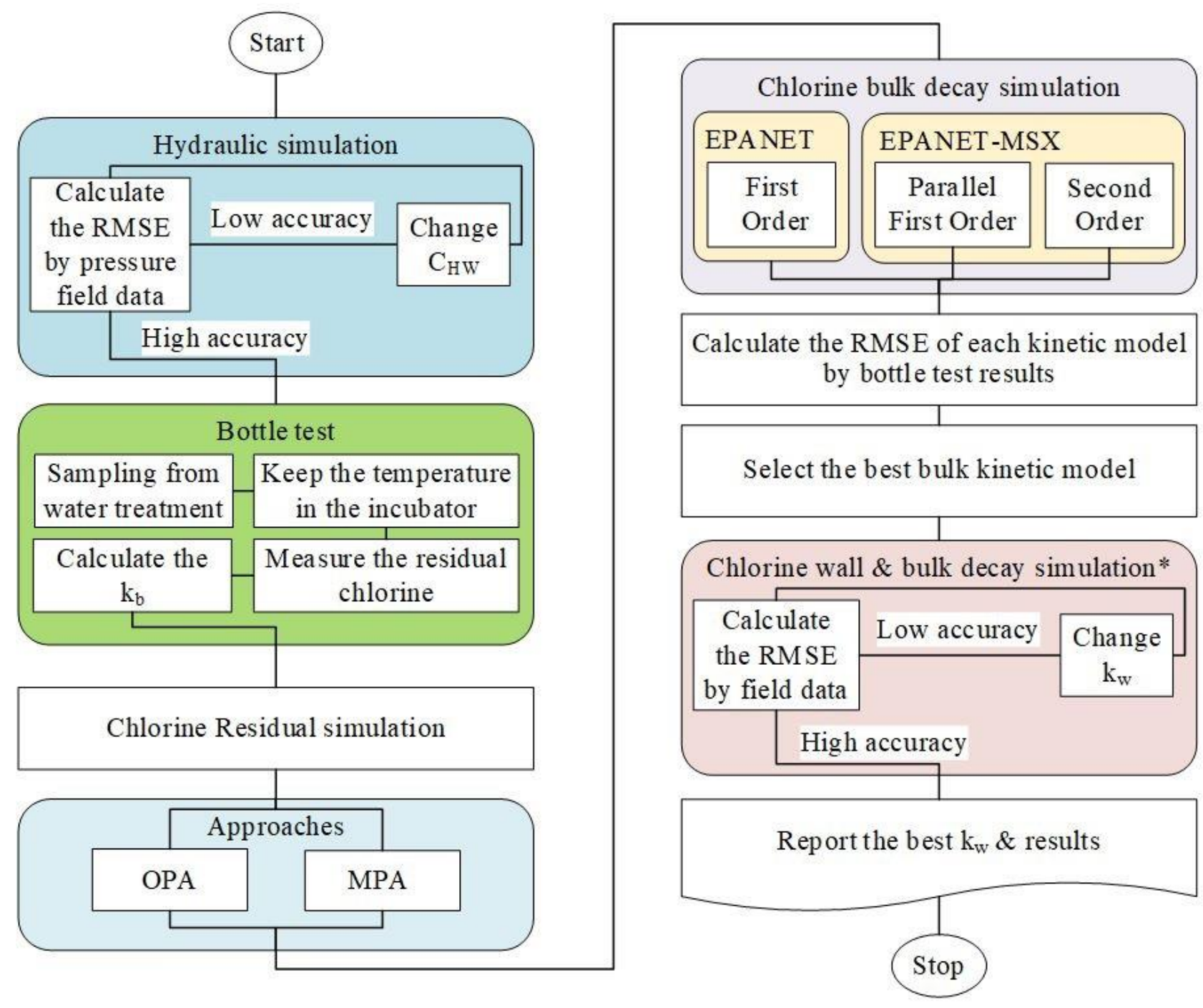

* Depending on the applied kinetics model, wall \& bulk decay are simulated in EPANET or EPANE-MSX

Figure 4: Flowchart of Simulation procedure in EPANET

\section{Results and discussion}

\subsection{Evaluating the results of the chlorine bulk decay models}

The simulation results of chlorine bulk decay kinetic models for OPA and MPA are

264 compared with the observations in bottle tests in Figure 5 and Figure 6 for summer 
RMSE of the results are tabulated in Table 4.

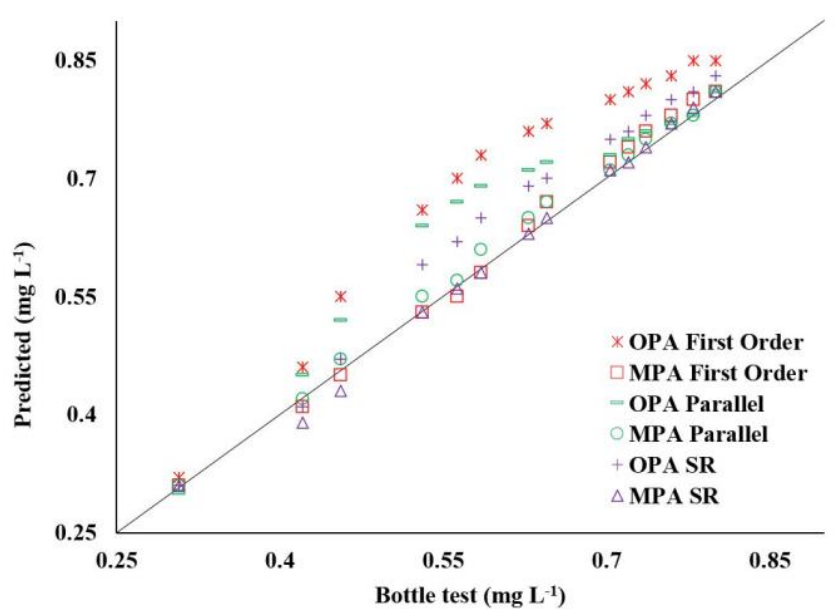

270 Figure 5: Correlation plot of bottle test and predicted chlorine concentration volumes at $\mathbf{T}=\mathbf{1 8}^{\circ} \mathrm{C}$

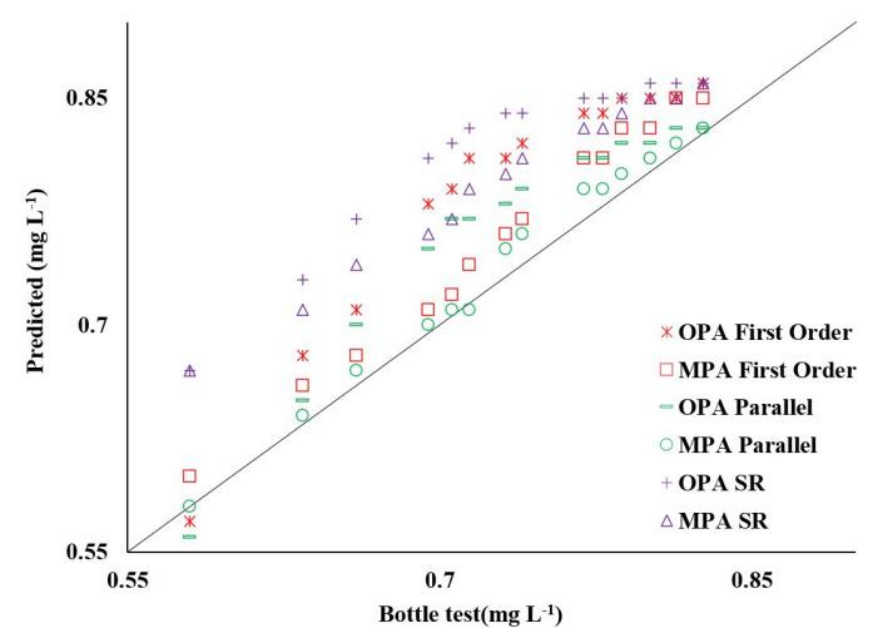

272 Figure 6: Correlation plot of bottle test and predicted chlorine concentration volumes $\mathbf{T}=6^{\circ} \mathrm{C}$

Table 4: RMSE volume between bottle test and predicted chlorine concentrations

\begin{tabular}{|c|c|c|c|c|c|}
\hline \multirow{2}{*}{ Season } & \multicolumn{2}{|c|}{ Simulated in: } & EPANET2.0 & \multicolumn{2}{c|}{ EPANET-MSX } \\
\cline { 2 - 6 } & $\mathrm{T}\left({ }^{\circ} \mathrm{C}\right)$ & Approach & First Order & Parallel & SR \\
\hline summer & 18 & OPA & 0.0954 & 0.0600 & 0.0425 \\
\hline
\end{tabular}




\begin{tabular}{|l|l|l|l|l|l|}
\hline & & MPA & 0.0147 & 0.0138 & 0.0116 \\
\hline \multirow{3}{*}{ winter } & \multirow{2}{*}{6} & OPA & 0.0646 & 0.0395 & 0.0900 \\
\cline { 3 - 6 } & & MPA & 0.0286 & 0.0114 & 0.0644 \\
\hline
\end{tabular}

274 According to Table 4, in the OPA simulation for $\mathrm{T}=18^{\circ} \mathrm{C}$, the $\mathrm{SR}$ and parallel models

275 with respectively RSME of 0.0425 and 0.0600 , estimate chlorine consumption more

276 accurate than the first order model with RMSE equal to 0.0954 . For $\mathrm{T}=6^{\circ} \mathrm{C}$ in the OPA,

277 the parallel model performs better than SR and first order models.

278 Applying MPA with different bulk decay coefficients for each part, results in a

279 significant improve in the results, as indicated in Table 4. Therefore, a similar level of

280 accuracy achieved the three simulated kinetic models in MPA and applying first order

281 kinetic model in MPA is more effective than applying more complex kinetic models in

282 OPA. According to Table 4, the SR model in $18^{\circ} \mathrm{C}$ and parallel model in $6^{\circ} \mathrm{C}$ in both

283 approaches have minimum RMSE and are selected for wall decay coefficient

284 determination.

$285 \quad$ 5.2. Chlorine wall decay simulation

286 After selecting the best bulk decay models, the wall decay coefficient volume, $\mathrm{k}_{\mathrm{w}}$

287 is estimated for the models. For this purpose, the model is run for a range of $\mathrm{k}_{\mathrm{w}}$ to obtain

288 the least RSME. In summer for example, the best wall decay coefficient of $0.04 \mathrm{~m} \mathrm{~d}^{-1}$ 
291 The coefficients are 0.09 and $0.01 \mathrm{~m} \mathrm{~d}^{-1}$ for the first and the second part, respectively.

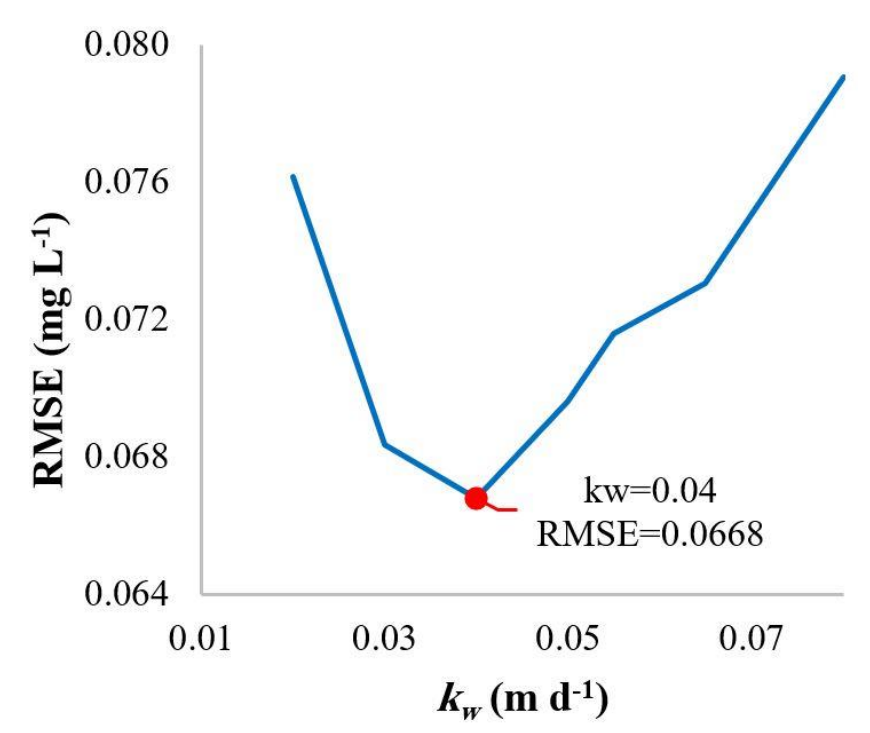
simulated chlorine concentration volumes in the OPA and MPA simulation with the

297 field measurements are shown in Figure 8 where volumes in the MPA are closer to the

298 measured volumes than the OPA. For the best bulk kinetic models (SR in summer and

299 parallel in winter), the results clearly indicate the superiority of the MPA compared to 300 conventional approach of OPA. 
MPA respectively.

305 due to the long route $(258 \mathrm{~km})$, wide range water velocity and different pipe

306 characteristics, significantly improve the accuracy of the simulation results. advance kinetic models in the MPA, does not significantly improve the results, compare

311 RMSE of 0.0294 and 0.0290 in summer and 0.015 and 0.016 in winter for the first order

312 model and the others, respectively.

Table 5: Wall decay coefficients by simulation

\begin{tabular}{|c|c|c|c|c|c|c|c|c|c|}
\hline \multirow{2}{*}{$\begin{array}{c}\mathrm{T} \\
\left({ }^{\circ} \mathrm{C}\right)\end{array}$} & \multirow[t]{2}{*}{ Approach } & \multirow[t]{2}{*}{ Parts } & \multicolumn{4}{|c|}{$\begin{array}{l}\text { Best bulk kinetic model } \\
\text { (SR or Parallel) }\end{array}$} & \multicolumn{3}{|c|}{ First Order Model } \\
\hline & & & & & $\mathrm{k}_{\mathrm{w}}$ & RMSE & $\mathrm{k}_{\mathrm{b}}$ & $\mathrm{k}_{\mathrm{w}}$ & RMSE \\
\hline \multirow{3}{*}{18} & OPA & All(0-82h) & & & 0.04 & 0.0668 & 0.286 & 0.08 & 0.090 \\
\hline & \multirow{2}{*}{ MPA } & First(0-18h) & & & 0.09 & \multirow{2}{*}{0.0294} & 0.583 & 0.15 & \multirow{2}{*}{0.029} \\
\hline & & Second(18-82h) & \multicolumn{2}{|c|}{0.557} & 0.01 & & 0.216 & 0.005 & \\
\hline 6 & OPA & All(0-92h) & 0.401 & 0.103 & 0.08 & 0.0543 & 0.103 & 0.08 & 0.064 \\
\hline
\end{tabular}




\begin{tabular}{|l|c|c|c|c|c|c|c|c|c|}
\hline \multirow{2}{*}{ MPA } & First(0-22h) & 0.401 & 0.204 & 0.1 & \multirow{3}{*}{0.015} & 0.204 & 0.13 & \multirow{2}{*}{0.016} \\
\cline { 3 - 5 } & & Second(22-92) & - & 0.062 & 0.05 & & 0.062 & 0.04 & \\
\hline
\end{tabular}

314
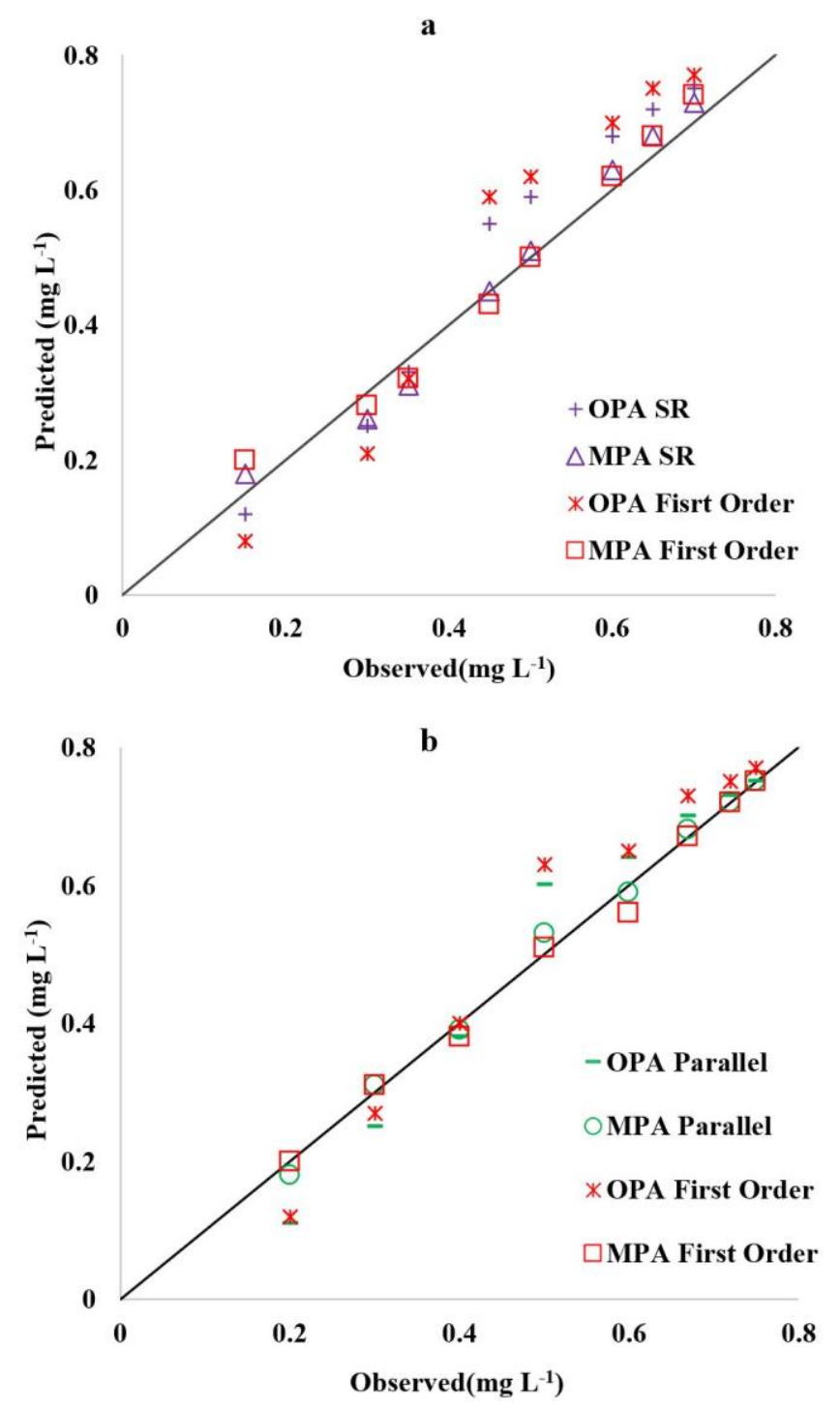

$317 \quad$ Figure 8: Comparison between observed and predicted chlorine concentration $\left(\mathrm{mg} \mathrm{L}^{\mathbf{- 1}}\right)$ in a) 
$322 \mathrm{~m}^{3} \mathrm{~s}^{-1}$. Hydraulic simulation of IWTL is performed through EPANET2.0 s/w and the

323 results are verified against pressure data collected at a number of nodes along the line.

324 Bulk decay coefficient is determined by bottle test in 6 and $18^{\circ} \mathrm{C}$ corresponding to

325 winter and summer water temperature, respectively. Residual chlorine concentration is

326 simulated via two approaches: one-part approach (OPA) and multi-part approach

327 (MPA) and the results are compared. Number of decay kinetic models are applied in

328 the simulation, including first order model (in EPANET2.0) and Parallel and SR models

329 (in EPANET MSX). The optimum wall decay coefficient is determined through the

330 calibration of the models with the measured chlorine concentration at the selected nodes

331 on the line. In the OPA, the parallel kinetic model in winter (RMSE=0.0543) and the

332 SR model in summer (RMSE $=0.0668)$ are the best kinetic models with the least RMSE

333 compared to the field data. In the OPA, the bulk decay coefficients of 0.401 and 0.103

$334 \mathrm{~d}^{-1}$ and wall decay coefficient of $0.08 \mathrm{~m} \mathrm{~d}^{-1}$ are derived, for the whole line in winter and

335 they are $0.590 \mathrm{~L} \mathrm{mg}^{-1} \mathrm{~d}^{-1}$ and $0.04 \mathrm{~m} \mathrm{~d}^{-1}$ in summer respectively.

336 In the MPA, no significant advantages found between the kinetic models. In the

337 former approach, RMSE of the first order and the best kinetics models are 0.0290 and

3380.0294 in summer, and 0.016 and 0.015 in winter. Applying different coefficients for 

applied for each parts of the line. Further research determines the optimum number of 351 divisions and the location of separation points on the line. each part (MPA) is more effective than applying most sophisticated kinetics models.

$0.062 \mathrm{~d}^{-1}$ and the wall decay coefficient is 0.13 and $0.04 \mathrm{~m} \mathrm{~d}^{-1}$ in winter and 0.583 , $0.216,0.15,0.005$ respectively in summer. Average RMSEs are changed from 0.078 to 0.029 in summer and 0.059 to 0.015 in winter between OPA and MPA respectively, indicating a considerable improvement in the accuracy of the simulation. In the simulation of the water transmission lines with the common OPA, advanced models behave more accurately than the first order model, while different kinetic models do not differ much in the MPA. It means that applying the simple and conventional first order model incorporated in EPANET2.0, results in an acceptable level of accuracy, provided that the appropriate decay coefficient is

\section{$\underline{\text { Declarations }}$}

\section{Availability of data and materials}

$354 \quad$ Not applicable. 
$356 \quad$ Not applicable.

\section{Funding}

$358 \quad$ Not applicable

\section{Authors' contributions}

$360 \quad$ Not applicable.

\section{Acknowledgements}

364 to the joint plan No. 3554 between IWWO and the University of Isfahan.

367 chlorine decay and THM formation under rechlorination conditions. Water Res.

$368 \quad 2003 ; 37: 2654-66$.

370 chlorine dose and prediction of THMs in a water distribution system. Sustain Environ

$371 \quad$ Res. 2012;22:31-8. 
373 models for water distribution systems. Water Res. 2011;45:4896-908. in Water Distribution Networks Using EPANET - Case Study. Civ Environ Res. 2013;3:100-16. stations for drinking water distribution system. Appl Water Eng Res. 2017;5:51-60. 
quality and rechlorination cost in water distribution systems. Urban Water J.

404 layout in water distribution systems. Water Res. 2014;58:209-20. 
410 Water Sci Technol Water Supply. 2013;13:1161-6.

411 20. Fisher I, Kastl G, Sathasivan A, Jegatheesan V. Suitability of chlorine bulk 412 decay models for planning and management of water distribution systems. Crit Rev 413 Environ Sci Technol. 2011;41:1843-82.

415 Manual. 2008;115.

417 distribution system of a town with 50000 inhabitants. UPB Sci Bull Ser D Mech Eng. $418 \quad 2012 ; 74: 103-14$. 
424 distribution systems using network modelling techniques: Case study in Seoul City.

425 Water Sci Technol Water Supply. 2004;4:421-9.

426 26. Forouzandeh Y, Dehnavi A, Shanehsazzade A. Application of Multiple-part

427 Method length of line to Improve the Simulation of Chlorine Decay in Big Isfahan

428 Water Conveyance Line. Water and Wastewater. 2020;31:1-11.

429 


\section{Figures}

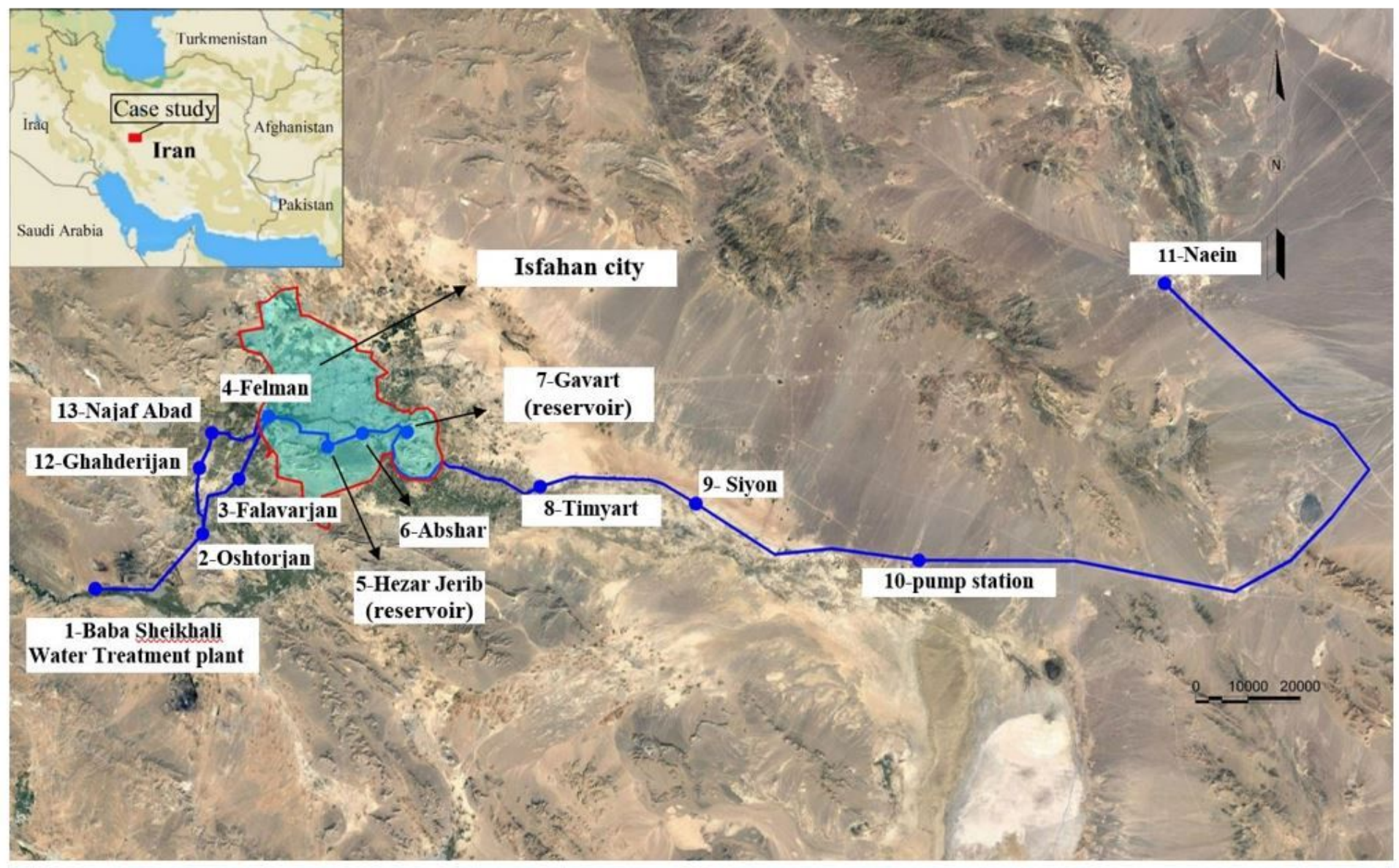

\section{Figure 1}

IWTL route Note: The designations employed and the presentation of the material on this map do not imply the expression of any opinion whatsoever on the part of Research Square concerning the legal status of any country, territory, city or area or of its authorities, or concerning the delimitation of its frontiers or boundaries. This map has been provided by the authors. 


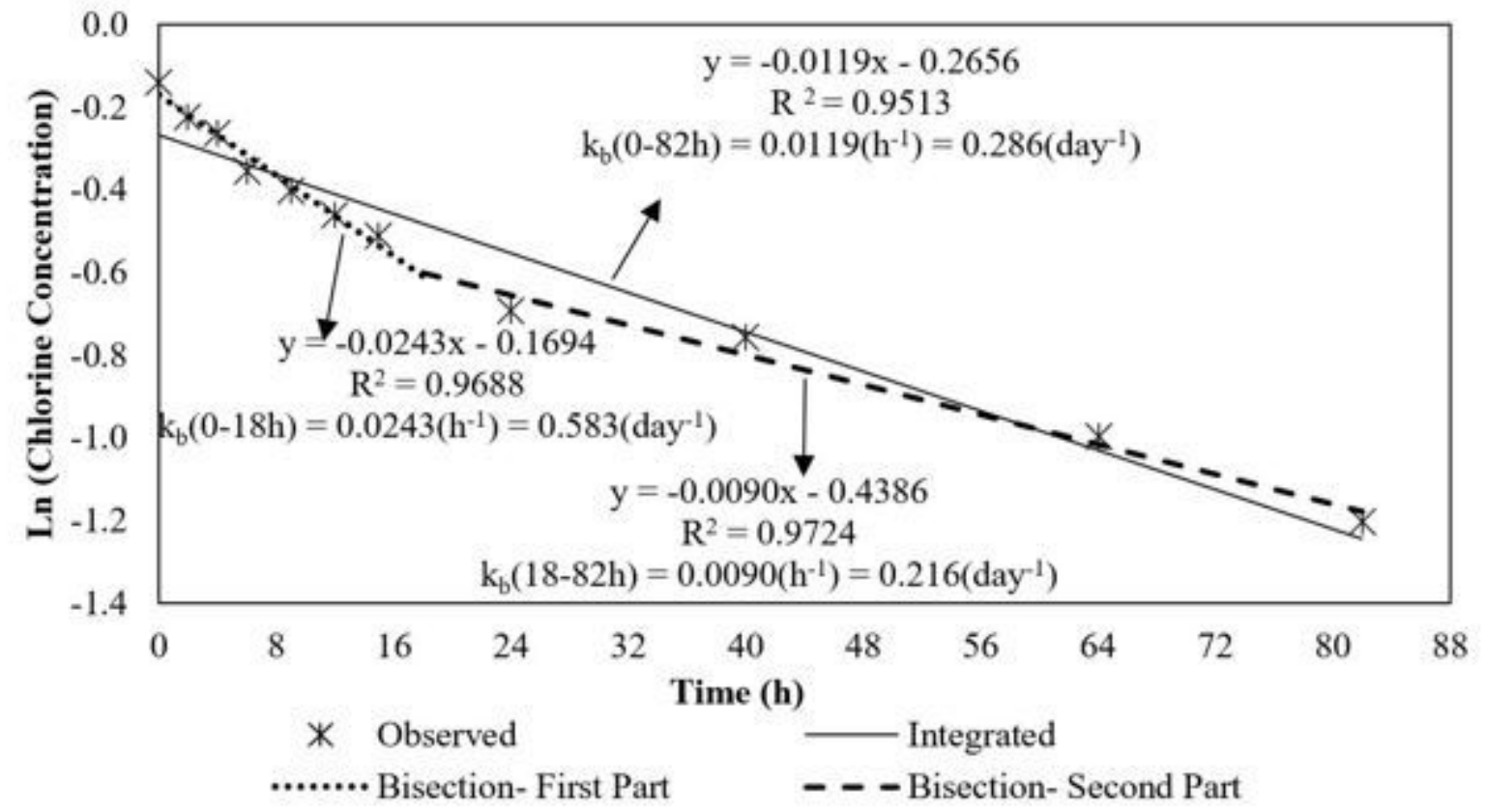

Figure 2

Bulk decay coefficient at $18^{\circ} \mathrm{C}$ with OPA and MPA using the bottle test

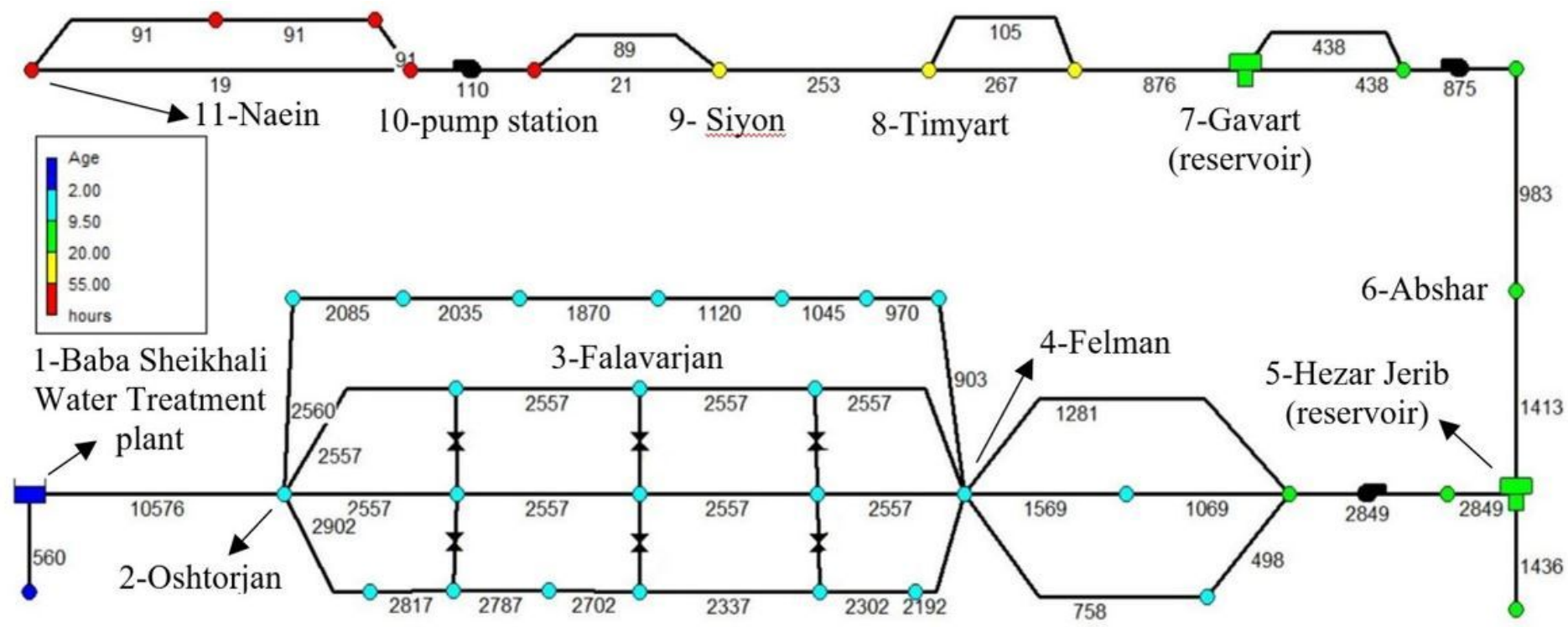

Figure 3

Schematic diagram of IWTL and simulation results in summer 

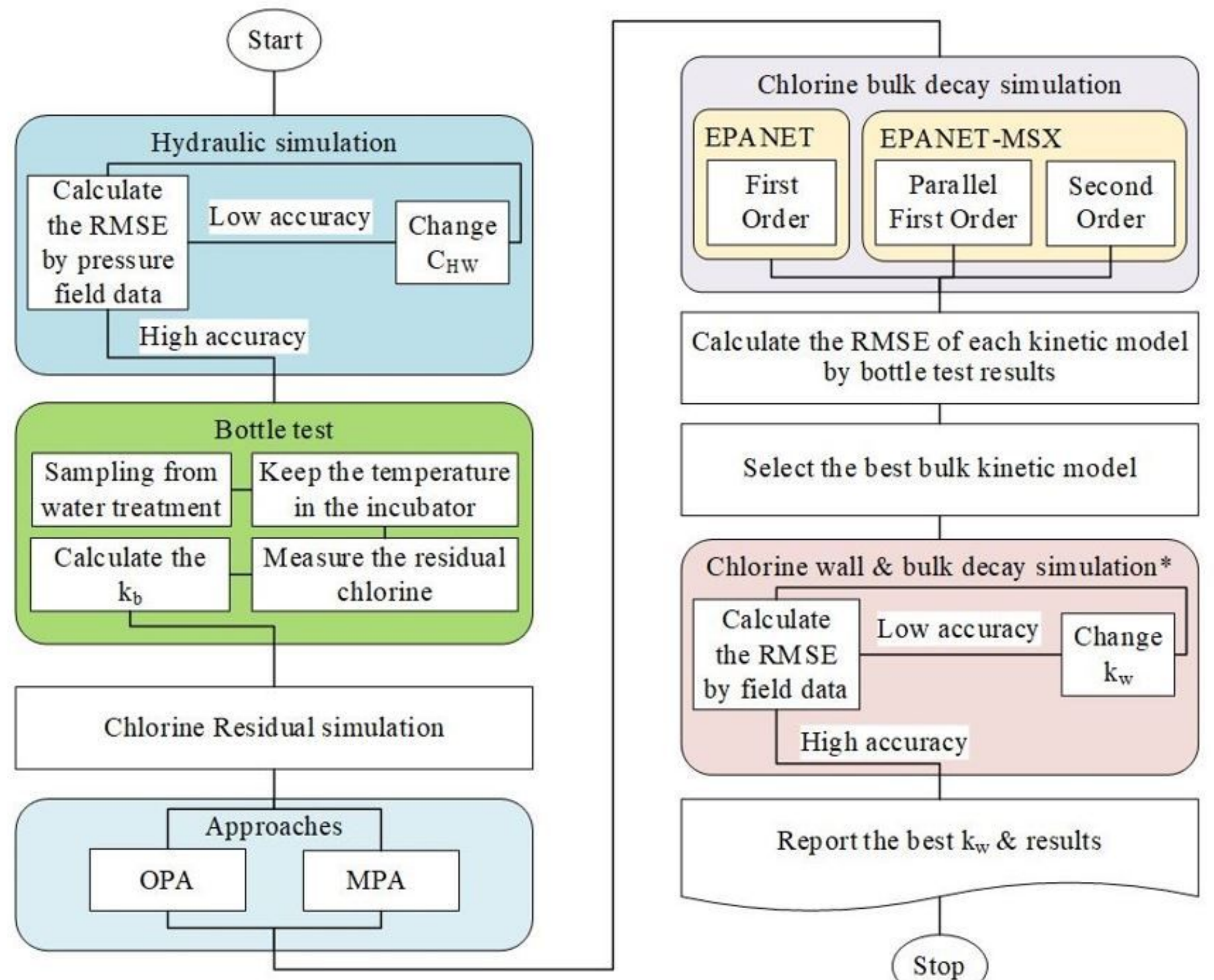

Calculate the RMSE of each kinetic model by bottle test results

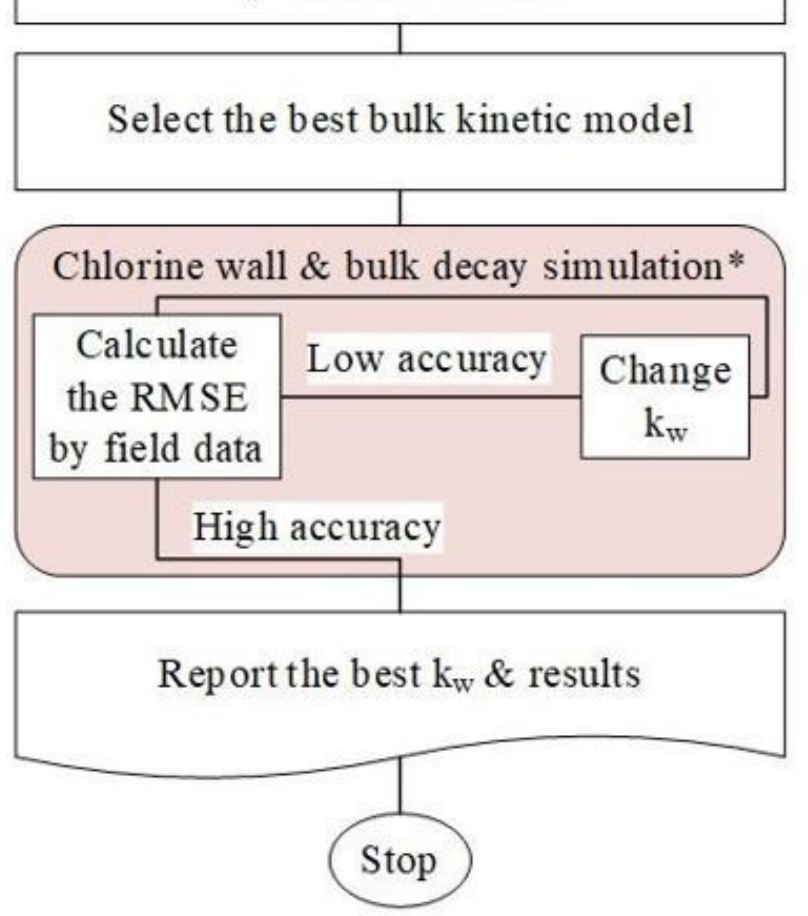

* Depending on the applied kinetics model, wall \& bulk decay are simulated in EPANET or EPANE-MSX

\section{Figure 4}

Flowchart of Simulation procedure in EPANET 


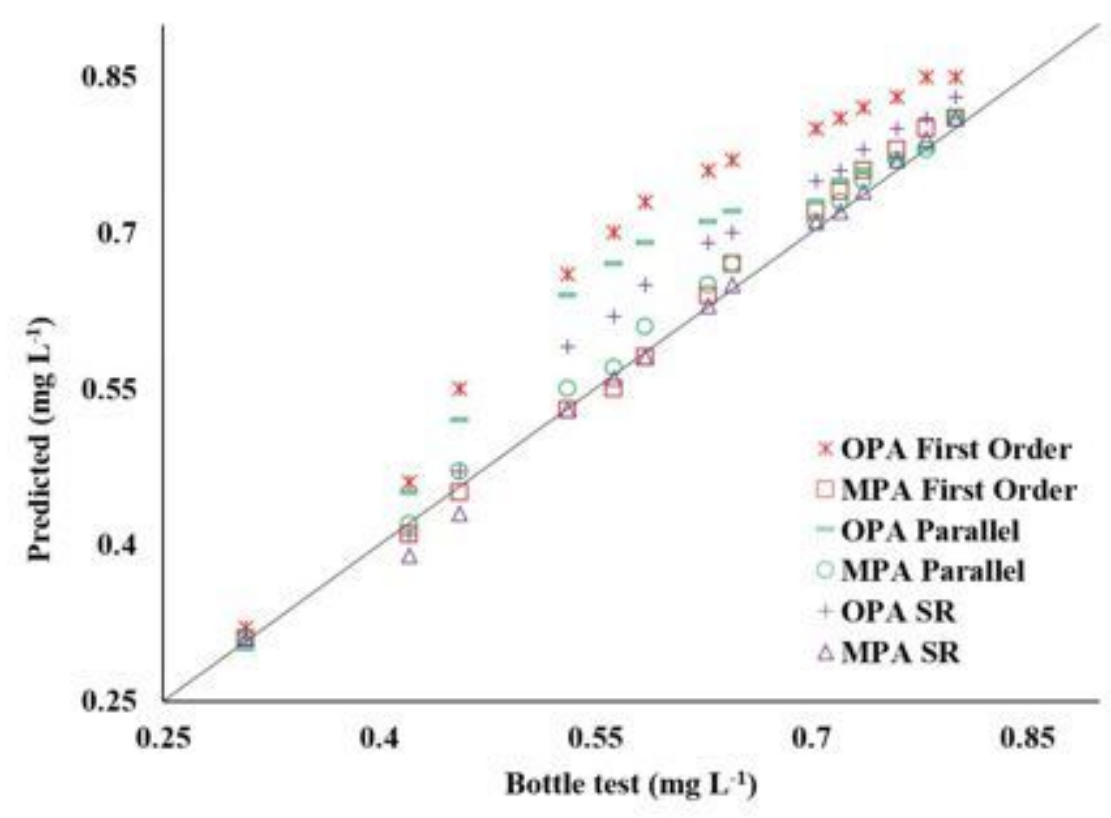

\section{Figure 5}

Correlation plot of bottle test and predicted chlorine concentration volumes at $\mathrm{T}=18^{\circ} \mathrm{C}$

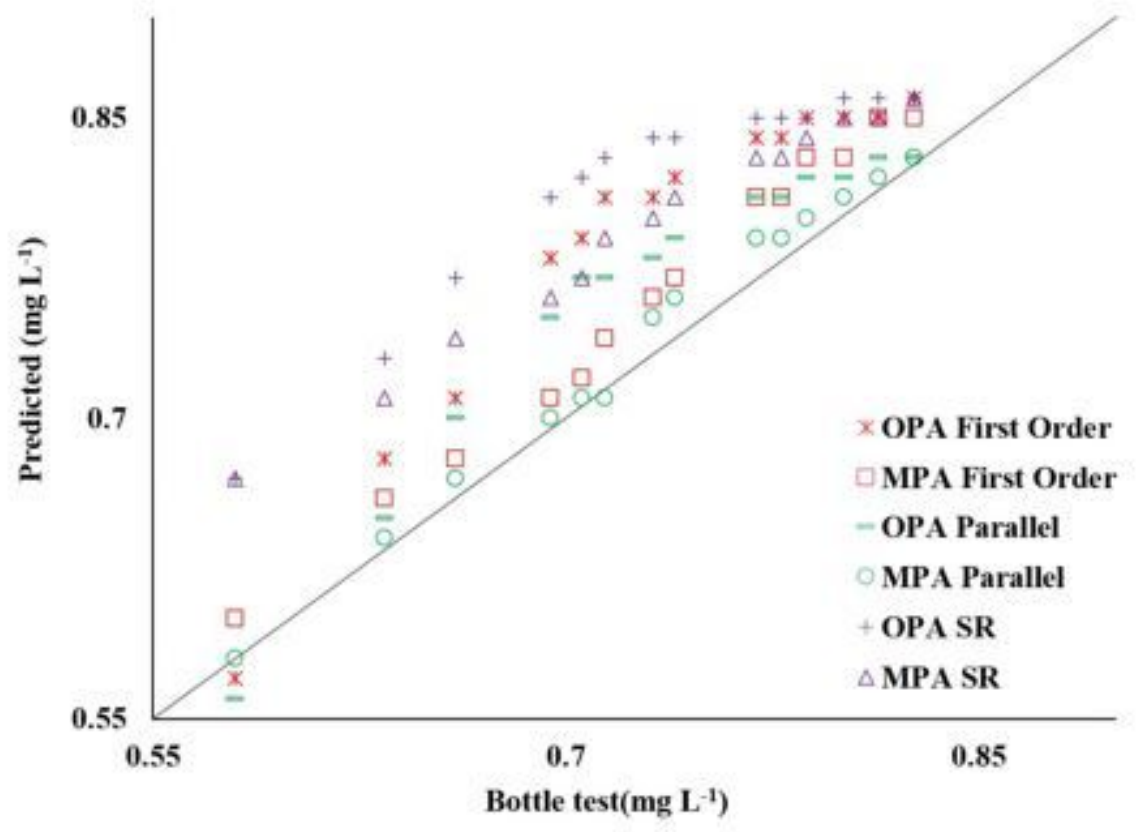

Figure 6

Correlation plot of bottle test and predicted chlorine concentration volumes $\mathrm{T}=6^{\circ} \mathrm{C}$ 


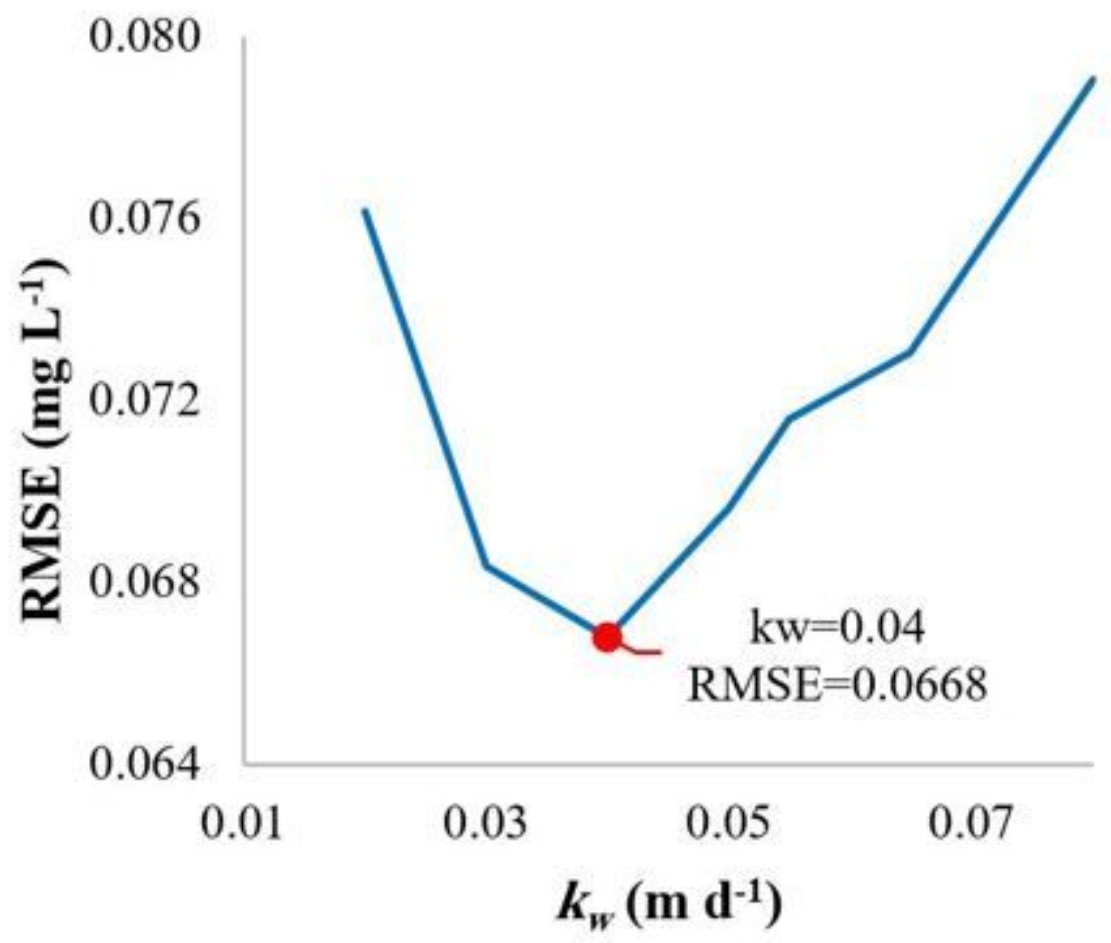

Figure 7

RMSE of simulation in wall first order model in the OPA in summer, $\mathrm{T}=18^{\circ} \mathrm{C}$ 

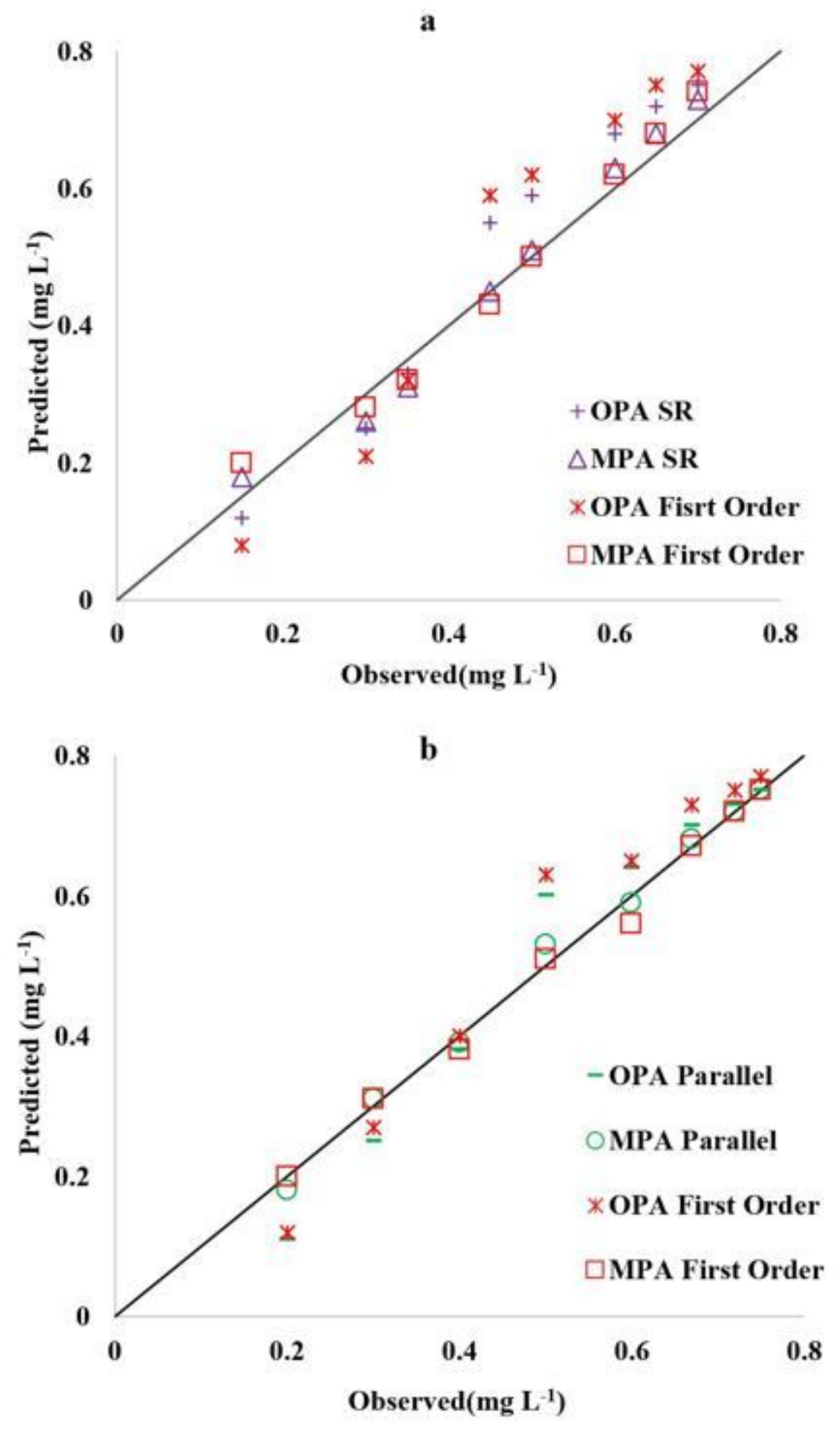

Figure 8

Comparison between observed and predicted chlorine concentration (mg L-1) in a) $\mathrm{T}=18^{\circ} \mathrm{C}$ and b) $\mathrm{T}=6^{\circ} \mathrm{C}$ 